\title{
EFFECTIVENESS OF COMPUTER-BASED FLIGHT SIMULATION
}

David A. Lombardo

Bowling Green State University

\begin{abstract}
The study measured the transfer effectiveness ratio from a computer-based flight simulation to a Link GAT I generic flight training device. The computer-based simulation consisted of Microsoft Flight Simulator software run on an IBM PS/2 Model 80 integrated with a set of Microflight Simulator flight controls by Wagner Computer Products.

There were 71 volunteer subjects who had zero flying experience piloting an airplane or using Microsoft Flight Simulator. Their ages ranged from 16 to 71 . The subjects were randomly divided between a control group and an experimental group. The experimental group consisted of 29 subjects who flew a basic attitude instrument pattern first on the computer-based flight simulator to private pilot criterion, then again in a Link GAT I flight training device to the same criterion. The control group consisted of 33 subjects who flew an identical basic attitude instrument pattern to criterion in the GAT I flight training device only. The experimental group was compared to the control group using a transfer effectiveness ratio. It was determined that one hour of training using computer-based flight simulation resulted in a saving of 22.8 minutes of training in the Link GAT $I$, yielding a transfer effectiveness ratio value of 0.38 .
\end{abstract}

\section{Introduction}

Over the past 30 years flight training devices have evolved from rudimentary analog procedures trainers to highly sophisticated digital flight simulators. Today's simulators are functionally indistinguishable from the specific aircraft they simulate. The evolution of flight simulators has been coordinated by the FAA and spurred onward by the air carriers and military because they had the resources to do so. General aviation, or that segment of aviation that is neither military nor air carrier, has had neither the organization or financial capability to participate in the development of the engineering criteria, rules and procedures which now govern flight simulation. As a result aircraft-specific flight simulators have evolved to a degree of technological sophistication and fidelity that requires 
an initial investment which, in many cases, exceeds the cost of the aircraft being simulated.

For the most part light aircraft simulation was limited to a few dedicated companies with minimal research and

development resources. This resulted in the development of flight training devices in which form followed function. In other words, the level of the device's fidelity was considered with respect to the training task it would address. The engineering orientation of these companies was to produce a low-cost training device that had sufficient fidelity to assure appropriate cause and effect relationships among the instruments and controls. The validity of this design orientation was further supported by Smode and Hall (1975) when they emphasized that training device design should be concerned with transfer of training. They argued that while the engineering approach to simulator fidelity is physical correspondence with the actual aircraft, it was more appropriate that the level of fidelity required should be determined by that which was actually necessary to promote learning. This very serious question of just how much fidelity is actually necessary to assure adequate transfer of training continues to plague the engineering-oriented National Simulator Program of the Federal Aviation Administration. The truth is there are numerous works which indicate that simulation fidelity need not be particularly high to accomplish a positive transfer of training (Povenmire \& Roscoe, 1971; Valverde, 1973; Swezey, 1989).

General aviation flight training device manufacturers subscribed to that orientation until the advent of the lowcost microprocessor. The flexibility afforded by the microprocessor caused both training device engineers and customers to seek greater and greater fidelity, but not necessarily for the right reasons. The engineers had a new found power in the microprocessor which afforded them the ability to increase fidelity through software improvement rather than the more costly hardware improvements. The customer, on the other hand, began demanding greater fidelity because students frequently complained that the training device didn't fly like the airplane. Unfortunately, the concept of what was necessary to assure transfer of training became lost in the shuffle as labor intensive programming costs began to cause the price of low-cost training devices to double and even triple. While trese modern flight training devices do not even begin to approach the initial cost of the multi-million dollar flight simulators, it is not uncommon for the cost of a generic, 
single engine flight training device to exceed $\$ 50,000$; with options it can easily exceed $\$ 100,000$. A few, very large general aviation flight schools may be able to justify the expense but most cannot. Clearly, there is a need for a lower-cost flight training device.

It was also microprocessor technology which made possible the video games that evolved into computer-based flight simulation. These new CBFS systems consist of representative flight simulation software which is operated on a personal computer. Several of today's CBFS software packages subjectively appear to have both good handling and performance characteristics which, within limits, improve as the computer's clock speed and graphics quality increase. If such CBFS devices offer a positive transfer of training to the airplane they could be readily adopted by general aviation flight training operations because of their low initial cost, typically less than $\$ 5,000$, and very low direct operating cost of pennies per hour.

While little research has been done in the area of CBFS, one project stands out. Hampton (1991) compared three training devices: The Link GAT I, the Frasca 141, and a CBFS system consisting of an IBM PC-XT computer with RGB color monitor integrated with a Novel Twist Cockpit Procedure Trainer and Flight Deck Software's Instrument Flight Trainer software. Among other issues, his research included basic attitude instrument flying training. He found that the Novel Twist CBFS provided basic attitude instrument training to at least the same standard as the GAT I and Frasca 141.

\section{Purpose}

The purpose of this study was to determine if Microsoft Flight Simulator, a commercially available software game, combined with a set of Microflight Simulator flight controls manufactured by Wagner Computer Products, had sufficient transfer of training value to warrant further research on the subject. For simplicity and cost considerations transfer of training was measured between the CBFS and a Link GAT I flight training device rather than an actual aircraft.

\section{Method}

\section{$\underline{\text { Subjects }}$}

Seventy-one subjects were used in the project and recruited through an advertisement in the local newspaper. The 
advertisement stated that the university was conducting flight simulation research and sought subjects at least 16 years of age with no piloting experience. Respondents included local residents, university students and staff, and a few individuals from outlying towns. The age range for the 23 female and 48 male subjects was 16 to 71 . See Table 1 for the distribution by age and gender of the 62 subjects who completed the project. In the interest of good will, the few individuals who applied that did have flying experience were allowed to participate without their results being recorded.

\begin{tabular}{|c|c|c|}
\hline AGE & FEMALE & MALE \\
\hline & $\mathbf{N}=19$ & $N=43$ \\
\hline 16 & 01 & \\
\hline 17 & & 02 \\
\hline 18 & 05 & 12 \\
\hline 19 & 06 & 19 \\
\hline 20 & 05 & 07 \\
\hline 21 & & 02 \\
\hline 22 & 01 & \\
\hline 33 & 01 & \\
\hline 37 & & 01 \\
\hline
\end{tabular}

Of the 71 subjects, nine were unable to complete the project leaving 62 subjects ( 19 female and 43 male). Five control group subjects were eliminated because they demonstrated progressively worse control of the Link GAT I resulting in the instructor making the subjective decision that further attempts on the part of the subject to reach criterion would be fruitless. See Table 2 for the total times of the individual control group subjects at the point of termination. 


\begin{tabular}{||l||}
\hline Table 2 Prematurely Terminated Control Group Subjects - \\
Total GAT I Time at Point of Termination \\
Subject \\
Total GAT I Time \\
1 \\
2 \\
3
\end{tabular}

Four experimental group subjects were unable to complete the project. Two subjects experienced motion sickness in the Link GAT I and were unable to complete that portion of the session. The computer-based flight simulation (CBFS) and GAT times for the first subject were 18 minutes 30 seconds and 14 minutes 30 seconds respectively, and 39 minutes 15 seconds and 41 minutes 45 seconds for the second subject. One experimental group subject successfully completed the CBFS training but exhibited progressively worse handling during the Link GAT I phase. The instructor terminated the subject's session at a GAT I time of 28 minutes 30 seconds; the subject's CBFS time was 39 minutes 30 seconds. One experimental group subject was never able to control the CBFS and was eliminated from the project.

\section{Flight Instructor}

The role of the flight instructor was pivotal to the success of the project. Recommendations set forth by Payne (1982) regarding the flight instructor as researcher were followed with the result that the same flight instructor was used throughout the life of the project from concept development through data collection. The instructor held an FAA flight instructor certificate for airplane single engine land and instrument, and was a graduate research assistant employed by the project.

\section{Apparatus}

A reconditioned Singer Link GAT I was used as a substitute for an aircraft to keep project costs within budgetary constraints. It was determined that the GAT I would be a reasonable choice of available training devices to be used in the project because prior research by Povenmire and Roscoe (1971) into its effectiveness in routine primary flight training indicated that the GAT I has a transfer 
effectiveness ratio to the aircraft of 1.0 up to approximately 11 hours of training. The GAT I incorporates three axes of motion (pitch, roll and yaw) and an instrument panel common to light, single engine aircraft including flight instruments, system instruments, electronic navigation equipment, and communication radios. The analog attitude instruments include: Attitude indicator, vertical speed indicator, heading indicator and airspeed indicator.

Prior to using the GAT I the experimental group used a CBFS system utilizing the Cessna 182 option of Microsoft Flight Simulator Version 3.0 software. The program was run on an IBM PS/2 Model 80 with $16 \mathrm{Mhz},-386$ processor and VGA color graphics monitor. A set of Microflight Simulator Model A300 , Version 3 flight controls manufactured by Wagner Computer Products was integrated with the IBM computer. The Microflight Controls were a representative array of single engine aircraft analog controls including yoke, rudder pedals, throttle, propeller, and mixture. It also included flap and gear switches. These controls interfaced with the Microsoft Flight Simulator software to provide representative cockpit instrument and control inputs and displays.

\section{Procedure}

\section{Experimental Procedure}

Seventy-one subjects were divided into two groups: An experimental group and a control group. All subjects were given a subject Informed Consent Form to verify they had no previous flying experience, to obtain a consent signature, and to collect data.

Subjects in the experimental group were given a written description in sufficient detail to assure the necessary knowledge of how to operate the CBFs controls. They were also given the opportunity to ask the instructor specific questions as necessary however subjects were not allowed to practice with the CBFS prior to the beginning of data collection. For the purpose of this experiment the subjects were only required to use the attitude indicator, vertical speed indicator, heading indicator, airspeed indicator, yoke, throttle and rudder pedals.

Once an experimental group subject understood the purpose of the appropriate flight controls and instruments as subjectively determined by the instructor, they were given a basic attitude instrument flight pattern to fly. The 
instructor preset the program so the simulated aircraft was at the appropriate altitude and in the appropriate configuration to maintain straight and level flight. The subjects were then given control of the simulation and performed as many repetitions of the pattern as necessary to reach criterion. Criterion was achieved when the subject could successfully fly the entire pattern as depicted within Federal Aviation Administration Private Pilot Flight Test Guide criterion, as follows:
Altitude :
$+/-100$ feet
Heading:
Airspeed :
$+1-10$ degrees
$+/-10$ knots
Bank Angle:
$+/-10$ degrees

The total practice flight time required to successfully complete one pattern within established criteria was recorded for each subject and is depicted in the distribution diagram in Table 3 .

Both groups were given a written description of how to operate the Link GAT I generic flight training device. Once a subject understood the purpose of the appropriate individual flight controls and instruments as determined subjectively by the instructor, they were given the basic attitude instrument flight pattern to fly. The instructor preset the GAT I at the appropriate altitude and in the appropriate configuration to maintain straight and level flight. The subjects were then given control of the GAT I and performed as many repetitions of the pattern as necessary to reach criterion.

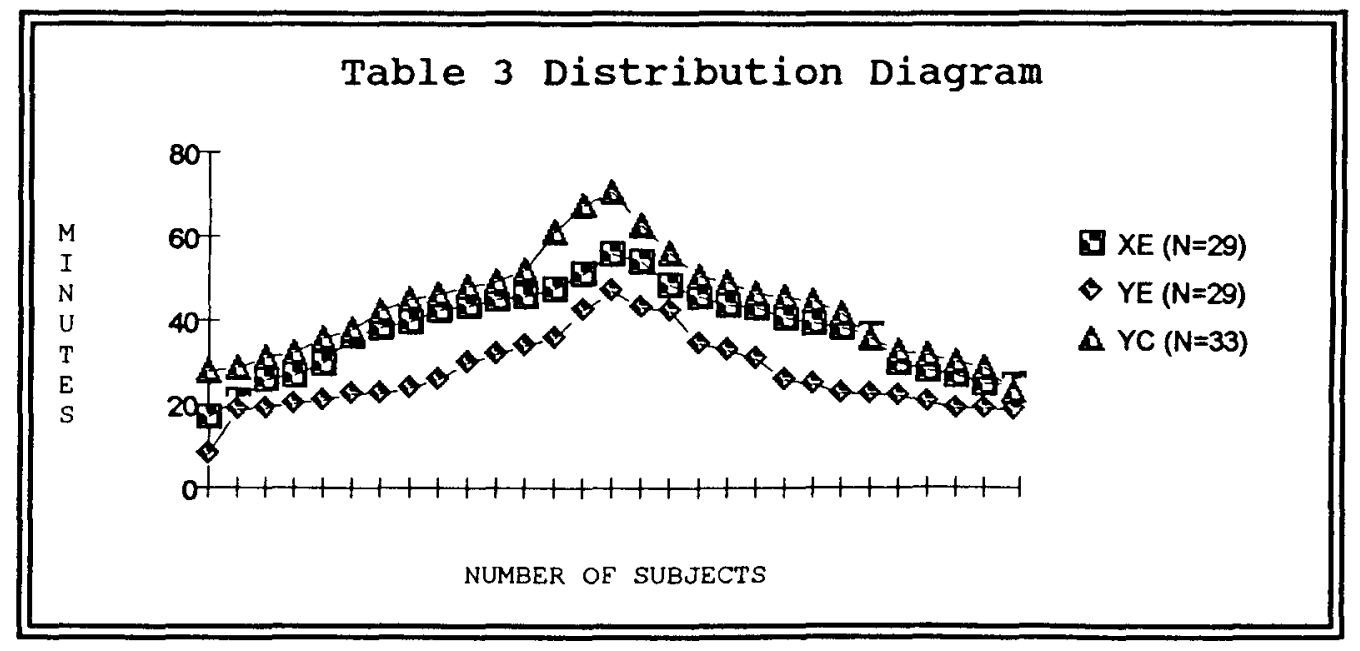


Both groups where given the same opportunity to learn the function of the instruments and controls, both flew the same pattern, and all subjects performed as many repetitions as necessary to complete one pattern within Private Pilot criterion. The total practice flight time required to reach criterion was recorded for each subject and is depicted in the distribution diagram in Table 3 .

\section{Data Collection and Reduction Procedure}

The basic attitude instrument flight pattern form also served as a standardized data collection form. The instructor timed the duration of each pattern to the nearest quarter of a minute and entered it on the form. Each control group subject had a single statistic (YC) indicating the total time required to achieve criterion in the Link GAT I. Each experimental group subject had two statistics: Total time to criteria using CBFS (Xe) and total time to criteria in the Link GAT I (Ye).

To determine transfer of training effectiveness, a transfer effectiveness ratio (TER) formula developed by Povenmire and Roscoe (1971) was employed. It was originally developed to meet the needs of a study measuring transfer of training from a flight training device to an aircraft. Transfer effectiveness ratio indicates time saved in the transfer (or operational) task, divided by the time required in the training device.

For the purposes of this study the TER will take into account the total duration of all pattern repetitions required to successfully complete one pattern within the criterion. The TER is calculated by the following formula:

Where:

$$
\mathrm{TER}=\frac{\mathrm{Yc}-\mathrm{Ye}}{\mathrm{Xe}}
$$

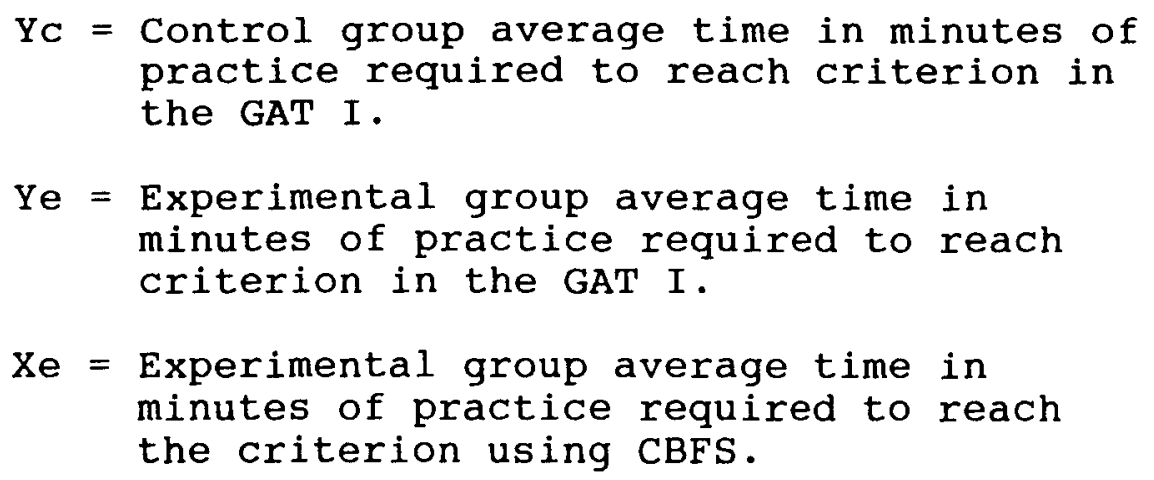


A positive number indicates there is some training benefit. Zero, or a negative number, indicates there is no training benefit. For instance, a TER of 0.5 would indicate that one hour of training with the experimental method would save approximately one-half hour of training utilizing the control group method.

\section{Results}

The 29 experimental subjects (Xe) had a cumulative time of 18 hours 10 minutes ( 18.2 hours) to criterion using the computer-based flight simulation software. This produced an average of 0.63 hours per subject to criterion. The same group had a total of 12 hours 42 minutes 30 seconds $(12.7$ hours) in the GAT I (Ye) to criterion which produced a 0.44 hours per subject average to criterion. The 33 control group subjects who were only exposed to the GAT I had a cumulative time to criterion of 22 hours 19 minutes 45 seconds (22.3 hours) or an average per subject time of 0.68 hours.

$\begin{array}{lll}\mathrm{Xe} & \mathrm{Ye} & \mathrm{YC} \\ \mathrm{N}=29 & \mathrm{~N}=29 & \mathrm{~N}=33 \\ 18: 10: 00 & 12: 42: 30 & 22: 19: 45 \\ 18.2 / 29=0.63 & 12.7 / 29=0.44 & 22.3 / 33=0.68\end{array}$

Using the transfer effectiveness ratio the data indicate that one hour of CBFS is equivalent to 0.38 hours of GAT I in the tasks researched.

$$
\begin{gathered}
(\mathrm{YC}-\mathrm{Ye}) / \mathrm{Xe}=\mathrm{TER} \\
(0.68-0.44) / 0.63=0.38 \\
\text { Discussion }
\end{gathered}
$$

\section{Discussion}

\section{Interpretation and Conclusions}

The purpose of the study was to determine if Microsoft Flight Simulator combined with a set of Microflight Simulator flight controls by Wagner Computer Products offers sufficient training effectiveness to warrant further research. A transfer effectiveness ratio of 0.38 indicates that one hour of practice on the CBFS system saved the subject approximately 23 minutes ( 0.38 hours) of comparable practice time in the Link GAT I flight training device. The training value for the zero-time pilot in the type of basic attitude flying training studied suggests a CBFS system has 
practical and cost-effective training value. It is the opinion of the researcher that the TER obtained in the study indicates sufficient effectiveness to warrant further investigation into the transfer effectiveness from computerbased flight simulation to an aircraft.

Recommendations

Further research should be conducted to determine the transfer effectiveness ratio to an actual single engine trainer aircraft. Possible areas to research include:

1. Introduction and practice in the use of basic aircraft controls and instruments in the visual control of the aircraft by zero or low experience student pilots.

2. Introduction and practice in the use of basic aircraft controls and instruments in restricted vision aircraft attitude instrument control by zero or low experience student pilots.

3. Introduction and practice of instrument flying terminal procedures by students training for the instrument rating.

4. Introduction and practice of instrument flying enroute procedures by students training for the instrument rating. 


\section{References}

Hampton, S. (1991). PC-Based simulation: An Alternative for teaching instrument flying skills. In A.R. Sadlowe (Ed.), PC-Based instrument flight simulation - A first collection of papers (pp. 13-17). The Winter annual meeting of the American Society of Mechanical Engineers. Atlanta, GA.

Payne, T.A. (1982). Conducting studies of transfer of learning: A Practical guide (Report No. AFHRL-TR-8125). Brooks Air Force Base, TX: HQ Air Force Human Resources Laboratory (AFSC).

Povenmire, H.K., \& Roscoe, S. (1971). An Evaluation of ground-based flight trainers in routine primary flight training. Human Factors. 13, 109-116.

Smode, A.F. and Hall, E.R. (1975). Translating information requirements into training device fidelity requirements. Proceedings Human Factors Society 19th Annual Meeting. Santa Monica, CA: Human Factors Society.

Swezey, R.W. (1989, June). Generalization, fidelity, and transfer of training. Human Factors Society Bulletin, pp. 4-5 .

Valverde, H.H. (1973). A review of flight simulator transfer of training studies. Human Factors. 15, 510-523. 